\title{
Is ferroptosis involved in ROS-induced testicular lesions in a varicocele rat model?
}

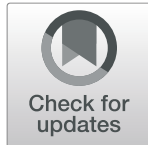

\author{
Erfaneh Shaygannia ${ }^{1}$, Mohammad H. Nasr-Esfahani ${ }^{2^{*}}$ (D), Fattah Sotoodehnejadnematalahi ${ }^{{ }^{*}}$ (D) and Kazem Parivar ${ }^{1}$
}

\begin{abstract}
Background: Ferroptosis is an iron-dependent cell death that is distinct from apoptosis. Based on excessive amounts of iron and reactive oxygen species in varicocele $(\mathrm{VCL})$ rats, we hypothesize that ferroptosis might be involved in VCL. In addition, since alpha-lipoic acid (ALA) was shown to have both antioxidant and anti-ferroptotic activity we assessed in the present work the status of ferroptosis in our varicocele model and the protective effect of ALA. To this end, 70 male Wistar rats were divided into 7 groups: control, sham and varicocele groups which were initially sacrificed 2 months after the operation to verify the induction of varicocele. A second batch of the same 3 groups were sacrificed 4 months after varicocele induction to evaluate the effect of ALA supplementation. The parameters measured were chromatin integrity (aniline blue and acridine orange staining), lipid peroxidation (BODIPY staining), testicular morphometry and iron content. In addition, redox (GSH and NADPH) and ferroptosis (Nrf2, Slc7a11, P53 and p-Jnk) markers were evaluated at 2 and 4 months post-operation.

Result: The alteration of the spermatic parameters made it possible to verify the induction of the varicocele. Iron accumulated well in the testicles during varicocele and decreased significantly following ALA treatment. Ferroptotic molecular markers at the mRNA and protein levels were not significantly altered. ALA supplementation did not alter NADPH values, but increased GSH levels.

Conclusion: Despite the increased accumulation of iron in the testes 2 and 4 months after surgical induction of varicocele, molecular evidence did not demonstrate the involvement of ferroptosis. This could be explained by the mosaic nature of the varicocele affecting some seminiferous tubules and not others which could mask variations in molecular markers. In parallel, our study confirms that ALA stimulates the NRF2 pathway.
\end{abstract}

Keywords: Varicocele, Reactive oxygen species, Ferroptosis, Alpha-lipoic acid

\section{Résumé}

(Continued on next page)

\footnotetext{
* Correspondence: mh.nasr-esfahani@royaninstitute.org;

sotoudehnejad@srbiau.ac.ir

${ }^{2}$ Department of Animal Biotechnology, Reproductive Biomedicine Research

Center, Royan Institute for Biotechnology, ACECR, Isfahan, Iran

${ }^{1}$ Department of Biology, School of Basic Sciences, Science and Research

Branch, Islamic Azad University, Tehran, Iran
}

(c) The Author(s). 2021 Open Access This article is licensed under a Creative Commons Attribution 4.0 International License, which permits use, sharing, adaptation, distribution and reproduction in any medium or format, as long as you give appropriate credit to the original author(s) and the source, provide a link to the Creative Commons licence, and indicate if changes were made. The images or other third party material in this article are included in the article's Creative Commons licence, unless indicated otherwise in a credit line to the material. If material is not included in the article's Creative Commons licence and your intended use is not permitted by statutory regulation or exceeds the permitted use, you will need to obtain permission directly from the copyright holder. To view a copy of this licence, visit http://creativecommons.org/licenses/by/4.0/ The Creative Commons Public Domain Dedication waiver (http://creativecommons.org/publicdomain/zero/1.0/) applies to the data made available in this article, unless otherwise stated in a credit line to the data. 
(Continued from previous page)

Contexte: La ferroptose est une mort cellulaire dépendante du fer qui est distincte de l'apoptose. Sur la base de quantités excessives de fer et d'espèces réactives de l'oxygène chez les rats varicocèles (VCL), nous avons fait I'hypothèse que la ferroptose pourrait être impliquée dans la VCL. Comme l'acide alpha-lipoïque (ALA) s'est avéré avoir des activités antioxydante et anti-ferroptotique nous avons dans ce travail testé le statut ferroptose dans notre modèle de rats VCL et évalué l'effet protecteur de ALA. Dans ce but, 70 rats mâles Wistar ont été divisés en plusieurs groupes: témoin, fictif et groupes varicocèle qui ont été initialement sacrifiés deux mois après l'opération pour vérifier l'induction de la varicocèle. Un deuxième lot des 3 mêmes groupes a été sacrifié 4 mois après l'induction de la varicocèle pour évaluer l'effet de la supplémentation en ALA. Les paramètres mesurés étaient l'intégrité de la chromatine (via les tests au bleu d'aniline et à l'orange acridine), la peroxydation lipidique (via le test BODIPY), la morphométrie testiculaire et la teneur en fer. De plus, les marqueurs redox (GSH et NADPH) et ferroptotique (Nrf2, Slc7a11, P53 et p-Jnk) ont été évalués 2 et 4 mois après l'opération.

Résultats: L'altération des paramètres spermatiques a permis de vérifier l'induction de la VCL. Le fer s'est bien accumulé dans les testicules pendant la VCL et a diminué de manière significative après le traitement ALA. Les marqueurs moléculaires ferroptotiques n'ont pas été modifiés de manière significative que ce soit en quantité d'ARNm et de protéines. La supplémentation en ALA n’a pas modifié la teneur en NADPH, mais a augmenté les niveaux de GSH.

Conclusions: Malgré l'accumulation accrue de fer dans les testicules 2 et 4 mois après l'induction chirurgicale de la VCL, les investigations au niveau moléculaire n'ont pas clairement démontré l'implication de la ferroptose. Cela pourrait s'expliquer par la nature mosaïque de la VCL qui affecte certains tubules séminifères et pas d'autres, ce qui pourrait atténuer les évaluations réalisées sur organe entier. En parallèle, notre étude confirme que l'ALA stimule la voie NRF2 stimulant la réponse anti-oxydante.

Mots-clés: Varicocèle, Espèces réactives de l'oxygène, Ferroptose, Acide alpha-lipoïque

\section{Introduction}

Programmed cell death or apoptosis plays a fundamental role in development, tissue homeostasis and various diseases. More recently, another process of programmed cell death, genetically and biochemically distinct from apoptosis, has been described $[1,2]$. This new cell death process called ferroptosis is iron-dependent and is further characterized by an accumulation of iron-dependent lipid peroxides [1, 2]. In contrast to apoptotic cells, ferroptotic cells have soft plasma membranes, high-density mitochondria with diminished or disappeared crista and a normal nucleus with intact chromatin [3].

One of the biochemical characteristics of a ferroptotic cell is the reduction of glutathione (GSH) and nicotinamide adenine dinucleotide phosphate (NADPH), the latter being necessary for the recycling of the former. In addition, ferroptotic cells have a distinct gene expression profile [4]. One of the pathways involved in ferroptosis is the cystine (Cys2)/Glutamate Antiporter System $\mathrm{x}_{\mathrm{c}}{ }^{-}$. This antiporter imports Cys 2 into cells and exports glutamate from them. Inside the cells, Cys2 is reduced to cysteine (Cys) and becomes GSH after the addition of glutamate and glycine [1, 3]. Under normal conditions, GSH is used to control lipid peroxidation. In ferroptosis the iron-induced excessive lipid peroxidation via a process called the "Fenton reaction", leads to GSH and NADPH depletion. It is therefore assumed that by inhibiting the Fenton reaction via iron chelation it is possible to limit ferroptosis [3].
The signaling pathways involved in ferroptosis are not fully understood, but it is proposed that the mitogenactivated protein kinase (MAPK) pathway plays an important role in this process. In addition, it has been revealed that P53 may also play a role in the ferroptosis pathway because it regulates the transcription of the Slc7a11 gene, a subunit of the $\mathrm{x}_{\mathrm{c}}{ }^{-}$system $[5,6]$. In addition, increased expression of Nrf2 (nuclear factor erythroid 2-related factor 2), a key player in antioxidant defense, stimulates the transcription of antioxidants such as Slc7a11 and Gpx-4 (Glutathione peroxidase 4) which have shown anti-ferroptotic activity $[7,8]$.

In varicocele (VCL) situations Gholirad et al. (2016) showed that due to reduced blood flow and increased testicular temperature, excessive amounts of iron are deposited in the testicles of varicocele rats [9]. Therefore, based on this observation, we hypothesize that ferroptosis could be activated. To test this hypothesis, we measured a set of markers of ferroptosis in the testes of a model rat in which VCL was induced. In addition, we evaluated the protective effect of alpha lipoic acid (ALA) on the level of ferroptosis, having previously shown that ALA could improve the structural and functional sperm parameters in this VCL rat model [10].

\section{Materials \& methods}

Seventy male Wistar rats were obtained from the breeding station of the Royan Institute of Biotechnology 
(Isfahan, Iran) and animal care was carried out as defined by the animal ethics committee of the ROYAN Institute. All rats were kept at a controlled temperature of $21{ }^{\circ} \mathrm{C}( \pm 2 \%)$, a humidity level of $65 \%( \pm 5 \%)$, a 12 -h light/ 12-h dark cycle and ad libitum access to food and water.

\section{Study design}

Briefly, seventy male rats weighing approximately 180 210 g (8-9 weeks) were randomly divided into 7 groups (10 rats/group). Twenty rats were assigned to the control group. Twenty rats were assigned to the sham panel and the remaining 30 rats underwent surgery to induce varicocele by partial blockage of the left renal testis vein $[11,12]$. Ten rats from each group ( $2 \mathrm{M}$ control, $2 \mathrm{M}$ sham and 2 $\mathrm{M}$ VCL) were sacrificed 2 months post-surgery for verification of varicocele induction. The remaining 10 rats from the control (4M control) and sham (4 M sham) groups were kept for up to 4 months after surgery. Half of the 20 animals in the VCL group were gavaged daily with R-ALA $(300 \mathrm{mg} / \mathrm{kg}$ of body weight, RAHA pharmaceutical company, Isfahan, Iran) dissolved in water $\left(\mathrm{V}^{\left.-I-\mathrm{ALA}^{+}\right)}\right.$while the remaining 10 rats were simply gavaged with water $\left(\right.$ V.I-ALA $\left.^{-}\right)$. Rats at 4 months post-surgery were sacrificed to assess semen parameters (Fig. 1). In order to avoid inter-observer variations, all the assessment were carried out by a single well-trained individual.

\section{Biometric and histological analysis}

After sacrifice, the left testis and epididymis were dissected and the volume of the testis was determined by the volumetric method using phosphate buffer saline (PBS), which is calculated by the difference between first and final volume. For the histological study, part of the testicular tissue was cut and fixed in bunion solution [13]. These samples were then dehydrated, fixed in paraffin and treated in $4-5 \mu \mathrm{m}$ sections on glass slides maintained at $4{ }^{\circ} \mathrm{C}$ until stained with hematoxilin and eosin [13]. In order to evaluate the mitotic index at least 200 seminiferous tubules were evaluated per slide (200x magnification). The ratio between round spermatids and primary spermatocytes was calculated for each sample. The percentage of spermatogenesis was evaluated by observing 200 seminiferous tubules on each slide (200x magnification). The observation of spermatozoa was evaluated as a positive spermatogenesis index while the absence of spermatozoa was considered a negative spermatogenesis index. The result was expressed as a percentage of the positive spermatogenesis index. Johnsen's score was evaluated according to the criteria originally described by Johnsen in 1970 [14].

\section{Sperm collection}

Sperm were collected after incubation of diced cauda epididymis in $2 \mathrm{ml}$ VitaSperm medium (Inoclon, Tehran,
Iran) at $37^{\circ} \mathrm{C}$ for $30 \mathrm{~min}$. Sperm concentration and epididymal sperm motility were evaluated using a sperm counting chamber (Sperm Meter; Sperm Processor, Aurangabad, India) and an optical microscope (OPTIKA B383LD2, Ponteranica, Italy). Sperm morphology was evaluated after staining with eosin-nigrosin (Merck, Germany). At least 100 cells were evaluated for each sample [15].

\section{Assessment of sperm DNA fragmentation, chromatin maturation and lipid peroxidation}

Sperm DNA fragmentation was assessed by acridine orange (AO) staining. Briefly, the air-dried smears were fixed with Carnoy fixing solution (methanol/acetic acid (3:1)) at $4{ }^{\circ} \mathrm{C}$ for $2 \mathrm{~h}$. Consequently, the slides were incubated with $\mathrm{AO}$ (final concentration: $0.1 \%$ in citrate buffer $\mathrm{pH}=2.5$, Merck, Germany) for $90 \mathrm{~min}$. Samples were then stabilized in PBS. A fluorescence microscope (BX51 TRF, Olympus, Tokyo, Japan) was used to evaluate the percentage of $\mathrm{AO}$ positive sperm. While sperm chromatin condensation was monitored using aniline blue $(\mathrm{AB})$ staining (final concentration: $5 \% \mathrm{AB}$ in $4 \%$ acetic acid, $\mathrm{pH}=3.5$, Sigma, USA) as described previously [10]. whereas an optical microscope was used to evaluate the percentage of sperm $\mathrm{AB}$ positive. For each test, at least 200-300 sperm were counted on each slide.

Sperm lipid peroxidation (LPO) was evaluated using 5 mM of C11 BODIPY 581/591 dye (D3861, Molecular Probes, Junction City, OR, USA) at $37^{\circ} \mathrm{C}$ for $30 \mathrm{~min}$. The percentage of LPO for each sample was assessed using a FACSCalibur (Becton Dickinson, San Jose, CA, USA) Flow Cytometer as already described [16].

\section{Assessment of testicular $\mathrm{Fe}^{3+}$ distribution}

The Perl's Prussian blue staining method was applied to evaluate the distribution of $\mathrm{Fe}^{3+}$ [17]. Briefly, $4 \mu \mathrm{m}$ sections of testes were dewaxed and dehydrated and exposed for $20 \mathrm{~min}$ to a mixture of potassium ferrocyanide (2\%) and hydrochloric acid (2\%) in a ratio of $1: 1(\mathrm{v} / \mathrm{v})$. The sections were then washed with water for $2 \mathrm{~min}$ and then fast red was used for $5 \mathrm{~min}$ at room temperature. Finally, the sections were successively washed with water and treated with alcohol and xylene. The images were obtained under the same conditions for all groups and the $\mathrm{Fe}^{3+}$ distribution was evaluated using the Image $\mathrm{J}$ software (version 1.42, National Institutes of Health, Bethesda, MD, United States) [17]. We used the surface to define the measurement window for the purpose of analyzing the quantity of $\mathrm{Fe}^{3+}$. We have also selected the pixel intensity unit for scaling the concentration values of $\mathrm{Fe}^{3+}$.All products necessary for this test were purchased from Merck (Germany). 


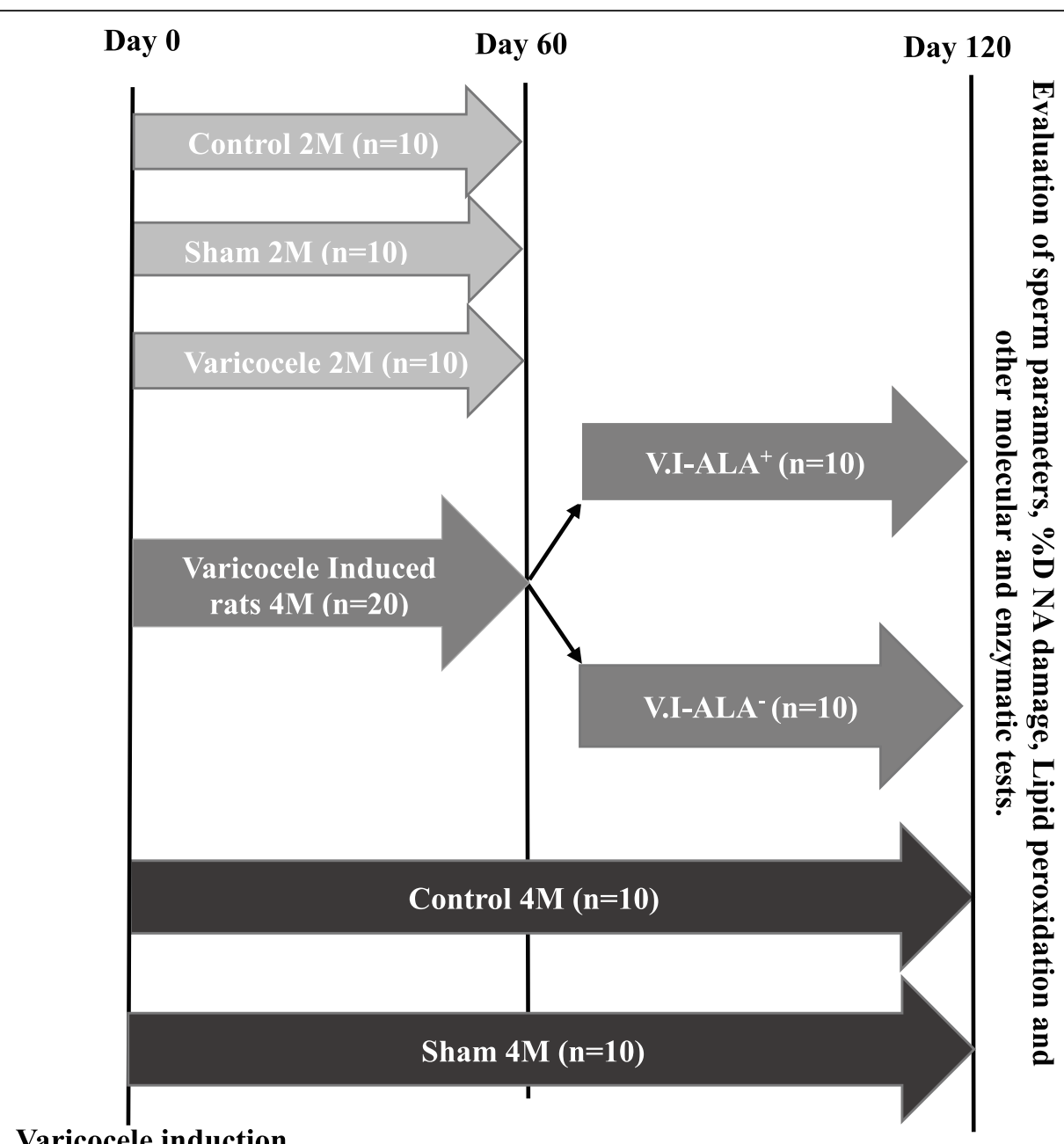

Fig. 1 Study design. Legend: 70 male rats were used in this study, 10 in each group. Control, sham 2 M, varicocele 2 M, V.I-ALA+ (varicocele (V.I) rats treated with alpha lipoic acid (ALA) for 2 to 4 months post induction of varicocele), V.I-ALA ${ }^{-}$(varicocele rats treated with water as solvent of ALA for 2 to 4 months post induction of varicocele), Sham $4 \mathrm{M}$ and control $4 \mathrm{M}$. At day 60 (2 M) and day 120 (4 M) sperm parameters, \%DNA damage, lipid peroxidation and other molecular and enzymatic tests were evaluated. ALA: Alpha lipoic acid, M: month post-surgery or varicocele induction (V.I). n: number of rats. +/- presence or absence of ALA

\section{Relative gene expression analyses}

To assess the level of expression of chosen genes, $50 \mathrm{mg}$ of frozen testicular tissue was cut and chopped for homogenization. Extraction of total RNA was performed using the Trizol reagent extraction method (Sigma, USA) [18]. RNA quality was evaluated by measuring absorbance at $260 \mathrm{~nm}$ with a Nanodrop spectrophotometer (Thermo Fisher Scientific, Wilmington, Delaware USA). The samples were then treated with Dnase1 (Fermentas, Burlington, Canada) to avoid DNA contamination. Complementary DNA (cDNA) synthesis was performed using the Takara Revert Aid First Strand cDNA Synthesis Kit (Takara, Otsu, Japan) on $2 \mu$ g of RNA according to the manufacturer's instructions. RT-PCR was performed using the $\mathrm{ABI}$ thermal cycling device according to the manufacturer's instructions (Thermo Fisher Scientific, Foster City, CA, USA). Specific primers (shown in
Table 1) were designed using Oligo 7 (Molecular Biology Insights, Inc., Cascade, CO, USA) and Beacon designer 7.5 software (Premier Biosoft, San Francisco, CA, USA). The final volume of each PCR reaction was $10 \mu \mathrm{l}$, containing $1 \mu \mathrm{l}$ of each forward and reverse primers (5 $\mathrm{pmol} / \mu \mathrm{l}$ each), $50 \mathrm{ng} \mathrm{cDNA}, 5 \mu \mathrm{l} \mathrm{SYBR}{ }^{\bullet}$ green and $0.2 \mu \mathrm{l}$ ROX. The reaction was carried out in triplicate. The qRT - PCR program was as follow: $15 \mathrm{~s}$ at $95^{\circ} \mathrm{C}$ and $10 \mathrm{~s}$ for the target genes, then $30 \mathrm{~s}$ at $72{ }^{\circ} \mathrm{C}$. All data collected by qRT-PCR were normalized to the expression data of the GAPDH mRNA as a housekeeping gene. Relative gene expression was reported as $2^{-\Delta \Delta C T}[18]$.

\section{Relative protein expression analyses}

Protein extraction was performed on frozen testicular tissue by the Trizol precipitation method. Protein concentrations were evaluated using the Bradford's test 
Table 1 Primers used in the study

\begin{tabular}{lllll}
\hline Genes & Forward Primer & Reverse Primer & Annealing Temp ( $\left.{ }^{\circ} \mathbf{C}\right)$ & Product Size $(\mathbf{b p})$ \\
\hline P53 & CCGACTATACCACTACCATAC & CACAAACACGACCTCAAAC & 64 & 147 \\
Nrf2 & GCCATTAGTCAGTCGCTCC & GTGCCTTCAGTGTGCTTCT & 61 & 98 \\
Slc7a11 & TGTCTCCAGGTATTCTATTT & CCAGAGAAGAGCATTATCATG & 54 & 138
\end{tabular}

$b p$ base pair, Nrf2 Nuclear factor erythroid 2-related factor, Temp Temperature, ${ }^{\circ} \mathrm{C}$ Degree Celsius

(Bio-Rad; USA). Equal amounts of each protein $(30 \mu \mathrm{g})$ were loaded onto $12 \%$ SDS polyacrylamide gels (PAGE) which were then transferred to PVDF membrane (BioRad; USA). Blocking solutions were prepared separately for each antibody. Nrf2 (1/500, Anti-rabbit, Abcam, USA), Slc7a11 (1/500, Anti-rabbit, Abcam, USA), Gpx4(1/1000, Anti-rabbit, Abcam, USA), p-Jnk (1/1000, Anti-mouse, Abcam, USA) and $\beta$-Actin (1/500, Antirabbit, Santacruz, USA) were used as primary antibodies. Polyclonal IgG-HRP goat anti-mouse (1/5000, Dako, Denmark) and IgG-HRP goat anti-rabbit (1/16000, Santacruz, USA) were then used as secondary antibodies. Detection was performed using the GE Amersham ECL and Western Blotting kits (Amersham; GE Health care) and autoradiography [19]. Signal quantification was performed using Image J software.

\section{Assessment of testicular GSH content and NADPH content} GSH content was evaluated according to the Ellman method [20] with some modifications. Briefly, $50 \mathrm{ng}$ of frozen testicular tissue was cut and homogenized using a soft homogenizer (Navand salamat, Uromiah, Iran). After addition of 5\% TCA (Tricholoro acetic acid) and centrifugation for $5 \mathrm{~min}$ the supernatant were recovered. To $500 \mu \mathrm{l}$ aliquot, $2 \mathrm{ml}$ phosphate solution and $500 \mu \mathrm{l}$ DTNB (5, 5'-dithio-bis-[2-nitrobenzoic acid]) were added. The GSH content was measured at $412 \mathrm{~nm}$ by spectrophotometry (Eppendorf, England). To specify the exact GSH content, a standard graph was established by preparing 5 to $50 \mathrm{mg} / \mathrm{ml}$ of pure glutathione in distilled water.

In order to evaluate the NADPH content, a NADP/ NADPH assay kit (ab65349, Abcam, Cambridge, MA, USA) was used and the protocol was performed according to the manufacturer's instructions.

\section{Statistical analysis}

All data collected in this study were analyzed using SPSS (SPSS 19, SPSS, Chicago, IL, USA), and figures and tables were prepared using Graph Pad Prism 6. The oneway ANOVA with Tukey HSD for Post-Hoc analysis to estimate differences between means was used to compare means between groups (more than 2 groups) for each parameter. The independent sample T-test was used to compare data between 2 groups (control and 2 months varicocele). The data are presented as mean \pm
SEM. $P<0.05$ indicates that a significant effect was observed. It should be noted that the objective of this study was not to make comparisons over time. The choice of the 2-month time-point was only intended to justify the establishment of varicocele as described earlier.

\section{Results}

\section{Sperm parameters}

As shown in Fig. 2a, the mean sperm concentration was significantly lower in VCL animals than in control animals at 2 months of age. Abnormal morphology was also significantly higher in the VCL group compared to control and sham animals. Sperm motility was also significantly lower in the group of VCL animals compared to the control group. The same observations apply to animals at 4 months of age (V.I-ALA ${ }^{-}$; Fig. 2b) with significantly lower sperm concentration, higher abnormal morphologies and lower motility compared to the control group and/or the sham animals. It is interesting to note that when ALA was administered to the animals $\left(\right.$ V.I-ALA ${ }^{+}$), a significant improvement of these 3 parameters was observed with a sperm concentration going up, abnormal morphology going down, and sperm motility going up.

\section{Morphometric and histological parameters}

At 2 months of age the ipsilateral testicular volume of the VCL animals $\left(1.01 \pm 0.07 \mathrm{~cm}^{3}\right)$ was significantly different $(p=0.01)$ to that of the control animals $(1.43 \pm$ $\left.0.05 \mathrm{~cm}^{3}\right)$. Regarding the other morphometric parameters monitored none were significantly different between the two groups of animals.

The mean mitotic index, spermatogenesis index and Johnson score were significantly decreased when comparing the VCL 2 months group to the control and sham groups at the same age (Table 2). Similarly, at 4 months, these same parameters were also significantly decreased when the VCL animals (V.I-ALA ${ }^{-}$) were compared to the control and sham groups. The addition of ALA (V.I$\mathrm{ALA}^{+}$group) significantly improves these parameters compared to VCL, although it did not bring them back to the level of the control animals (Table 2).

The mean diameter of the testicular tubules was slightly but significantly decreased in VCL animals compared to controls at 2 months of age but not against the sham group (Table 2). The situation was not worse at 4 


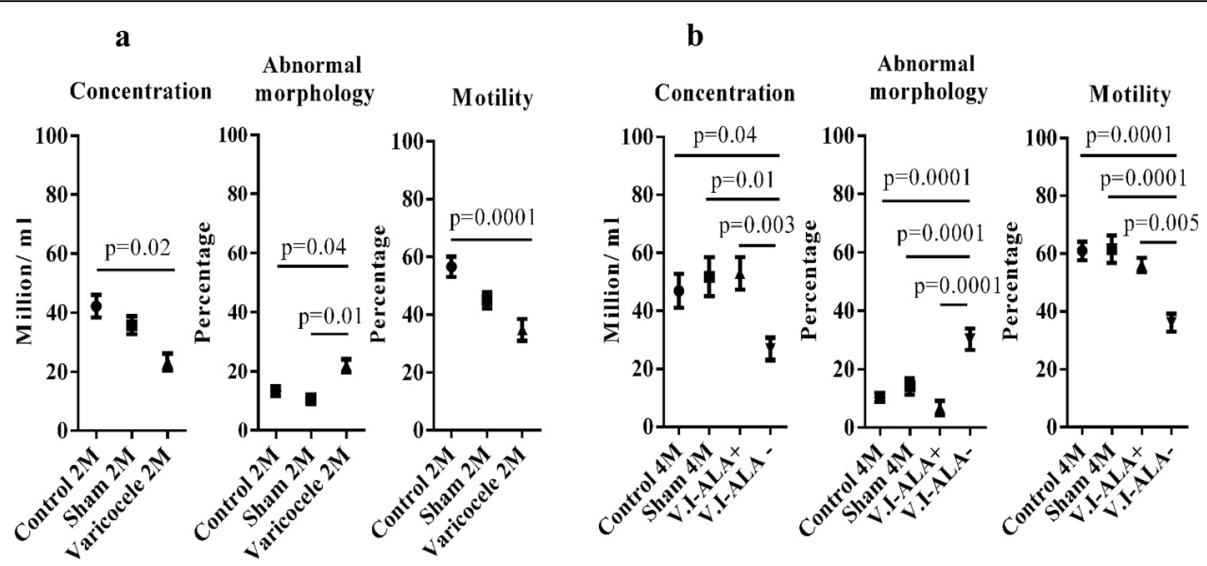

Fig. 2 Comparison of sperm parameters. Legend: Comparison of sperm parameter between groups at 2 (a) and 4 (b) months post-surgery or induction of varicocele. Sperm concentration and motility decreased significantly after $2 \mathrm{M}$ varicocele compared to the $2 \mathrm{M}$ control, while the abnormal morphology showed a significant increase. At 4 months, sperm concentration and motility decreased in the V.I-ALA group, compared to the V.I-ALA ${ }^{+}$group and the control group. Abnormal morphology increased significantly in the V.I-ALA ${ }^{-}$group compared to the $4 \mathrm{M}$ control group, the $4 \mathrm{M}$ sham group and the V.I-ALA ${ }^{+}$group. V.I-ALA ${ }^{+}$: varicocele rats treated with ALA for 2 to 4 months post induction of varicocele, V.I$\mathrm{ALA}^{-}$: varicocele rats treated with water as solvent of ALA for 2 to 4 months post induction of varicocele. Statistical analysis (one way ANOVA) for each time point ( 2 or $4 \mathrm{M}$ ) and for each parameter was carried out between groups and $p$-value is provided for the groups which showed significant difference (All the data were presented as Mean \pm SEM). M: month post-surgery or varicocele induction (V.I). V.I-ALA ${ }^{+}$: varicocele rats treated with alpha lipoic acid, V.I-ALA-: varicocele rats treated with water as solvent

months of age, as we only recorded a tendency to decrease. ALA supplementation restored testicular tubule diameter to that of the control animals (Table 2).

The histological evaluation of the testes by hematoxilin and eosin staining is presented separately (Fig. 3). As can be seen, the seminiferous tubules are intact in the control and sham group and in the 2 and 4 month

Table 2 Comparison of histological parameters and Johnson score between groups

\begin{tabular}{lllll}
\hline Group & $\begin{array}{l}\text { TD } \\
(\boldsymbol{\mu m})\end{array}$ & $\begin{array}{l}\text { MI } \\
(\mathbf{\%})\end{array}$ & $\begin{array}{l}\text { SP } \\
(\mathbf{\%})\end{array}$ & JS \\
\hline $\begin{array}{l}\text { Control } \\
(\mathbf{2} \mathbf{M})\end{array}$ & $8.07 \pm 0.02 \mathbf{a}$ & $68.24 \pm 0.39 \mathbf{d}$ & $90.21 \pm 0.52 \mathbf{h}$ & $9.41 \pm 0.57 \mathbf{I}$ \\
$\begin{array}{l}\text { Sham } \\
(\mathbf{2} \mathbf{M})\end{array}$ & $7.80 \pm 0.26$ & $67.52 \pm 0.09 \mathbf{e}$ & $89.21 \pm 0.45 \mathbf{i}$ & $8.16 \pm 0.75 \mathbf{~ m}$ \\
V.I (2 M) & $7.38 \pm 0.04 \mathbf{a}$ & $31.92 \pm 0.78 \mathbf{d e}$ & $30.27 \pm 0.93 \mathbf{h i}$ & $6.04 \pm 0.45 \mathbf{~ I m}$ \\
$\begin{array}{l}\text { Control } \\
(\mathbf{4} \mathbf{M})\end{array}$ & $7.97 \pm 0.31 \mathbf{b}$ & $67.35 \pm 0.79 \mathbf{f}$ & $90.04 \pm 1.05 \mathbf{j}$ & $9.84 \pm 1.25 \mathbf{n}$ \\
$\begin{array}{l}\text { Sham } \\
(\mathbf{4} \mathbf{M})\end{array}$ & $7.68 \pm 0.17$ & $67.08 \pm 0.47 \mathbf{g}$ & $88.00 \pm 0.57 \mathbf{k}$ & $9.00 \pm 0.30 \mathbf{o}$ \\
V.I-ALA $^{-}$ & $7.44 \pm 0.16 \mathbf{b c}$ & $29.88 \pm 1.42 \mathbf{f g}$ & $32.27 \pm 0.74 \mathbf{j k}$ & $5.43 \pm 0.58 \mathbf{n o}$ \\
V.I-ALA $^{+}$ & $8.10 \pm 0.07 \mathbf{c}$ & $57.92 \pm 0.44 \mathbf{f g}$ & $67.56 \pm 0.97 \mathbf{j k}$ & $7.53 \pm 0.15 \mathbf{n o}$ \\
\hline
\end{tabular}

In the $2 \mathrm{M}$ VCL group, measures of MI, SP and JS showed a significant decrease compared to the control and sham groups. While TD showed a significant decrease compared to the control but not sham group. At 4 months, measures of TD, MI, SP and JS were significantly decreased in the V.I$\mathrm{ALA}^{-}$group compared to the control and treated group (V.I-ALA $\left.{ }^{+}\right)$. ALA Alpha lipoic acid, $M$ Month post-surgery or varicocele induction (V.I), TD Tubular diameter, EH Epithelium height, MI Mitotic index, SP Spermatogenesis percentage and JS Johnson score. Statistical analysis (one way ANOVA) for each time point ( 2 or $4 \mathrm{M}$ ) and for each parameter was carried out between groups and the groups which showed significant different ( $p$-value $<0.05$ ) were defined by common alphabetic letters groups (Fig. 3a, b and d, e), while the seminiferous epithelium appears vacuolar and spermatogenesis is disturbed in the varicocele group at 2 months (Fig. 3c). Similarly, deformed seminiferous tubules with immature germ cells present in the lumen are visible in the V.IALA $^{-}$group (Fig. 3f), whereas all these abnormalities were almost absent in the V.I-ALA ${ }^{+}$group (Fig. 3g).

\section{Testicular Fe3+ distribution}

Perl's staining results revealed that the mean distribution of testicular $\mathrm{Fe}^{3+}$ was significantly higher in the VCL groups than in the control and sham groups whatever the age. The ALA treatment significantly reduced the testicular $\mathrm{Fe}^{3+}$ representation compared to the VCL group (Table 3).

\section{Sperm chromatin maturation, DNA fragmentation and lipid peroxidation}

As shown in Fig. 4A and $B$, the percentages of aniline blue $(\mathrm{AB})$ positive spermatozoa in VCL animals at either 2 or 4 months of age were significantly higher than in control and sham animals at the same ages. ALA supplementation significantly reduced the percentage of $A B$ positive spermatozoa to the level of control animals.

With regard to DNA fragmentation (Fig. 4A and B), the percentages of acridine orange (AO)-positive sperm were also significantly higher in the VCL groups compared to the control and sham animals regardless of age. Here again, the ALA treatment significantly reduced the percentage of AO-positive sperm but failed to bring it back to the level of the control animals. 


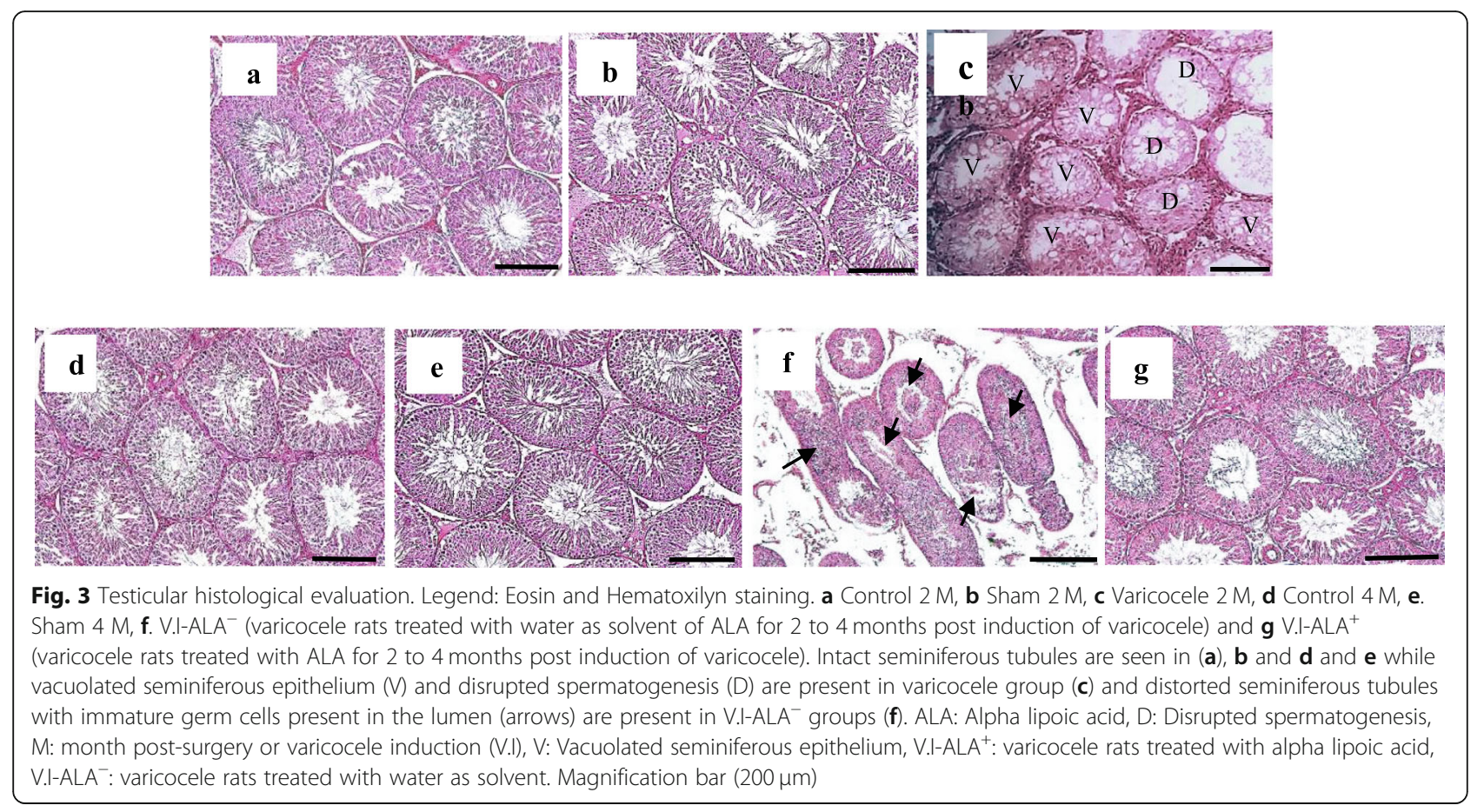

Similarly, evaluation of lipid peroxidation of sperm membranes by the Bodipy C11 probe showed that mean percentages of positive spermatozoa were significantly higher under VCL conditions compared to control and sham animals at all ages. Treatment with ALA significantly reduced the percentage of positive spermatozoa but again, it did not reach the level of the control animals (Fig. 4C). The aniline blue and acridine orange stains are shown in Fig. 4C (a and b, c, respectively) while Figs. 4D and E show the bodipy C11 charts.

\section{Relative expression of ferroptosis markers P53, Nrf2 and Slc7a11}

Figure 5a shows that although the three monitored ferroptosis markers tended to accumulate in greater proportion in 2 months old VCL animals compared to control animals, only the accumulation of $N r f 2 \mathrm{mRNA}$ was significantly different. Intriguingly, in VCL animals at 4 months of age $N r f 2$ mRNA accumulation was not different to that of control animals (Fig. 5b). At this age, it is also intriguing that the accumulation of Slc7a11
mRNA decreased in VCL animals compared to controls and, that ALA supplementation resulted in a significant increase in this mRNA steady state level (Fig. 5b).

Since, beside transcriptional activation, signaling cascades may rely on post-transcriptional responses leading to higher level of proteins we have monitored the Nrf2 and Slc7a11 protein contents in control and VCL animals. Reflecting the weak transcriptional up-regulation, we found that the Nrf2 and Slc7a11 protein content of VCL animals were not that different to that of control animals whatever their age (2 months or 4 months; Fig. 6a, b). Interestingly, at 4 month of age, ALA supplementation resulted in a higher level of Nrf2 protein content (which was statistically significant only when compared to V.I-ALA animals but not to control animals; Fig. 6b). No differences were recorded in any conditions for Slc7a11 (Fig. 6a, b). Western blot bands are presented in Fig. 6c.

\section{Relative expression of $\mathrm{p}$-Jnk and Gpx-4 proteins}

Since JNK and Gpx-4 are known targets for the markers of ferroptosis evaluated above, we monitored the

Table 3 Comparison of percentage of $\mathrm{Fe}^{3+}$ distribution between groups

\begin{tabular}{|c|c|c|c|c|c|c|c|}
\hline Group & Control(2 M) & Sham (2 M) & V.I (2 M) & $\begin{array}{l}\text { Control } \\
(4 \mathrm{M})\end{array}$ & Sham (4 M) & V.I-ALA & V.I-ALA ${ }^{+}$ \\
\hline Mean \pm SEM & $9.72 \pm 0.24 \mathbf{a}$ & $8.90 \pm 0.12 \mathbf{b}$ & $37.15 \pm 0.57 \mathbf{a b}$ & $9.56 \pm 0.26 c$ & $9.48 \pm 0.28 \mathbf{d}$ & $52.65 \pm 1.47 \mathbf{c d}$ & $14.96 \pm 0.24 \mathbf{c d}$ \\
\hline
\end{tabular}

There is a significant increase in $\mathrm{Fe}^{3+}$ accumulation in the $2 \mathrm{M}$ varicocele group compared to the $2 \mathrm{M}$ control and sham groups. Fe ${ }^{3+}$ accumulation decreased significantly in the V.I-ALA ${ }^{+}$group compared to the V.I-ALA, $4 \mathrm{M}$ control and sham groups. ALA Alpha lipoic acid, M: month post-surgery or varicocele induction (V.I), V.I-ALA ${ }^{+}$: varicocele rats treated with $\mathrm{ALA}^{+}$for 2 to 4 months post induction of varicocele, V.I-ALA ${ }^{-}$: varicocele rats treated with water as solvent of ALA for 2 to 4 months post induction of varicocele. Statistical analysis (one way ANOVA) for $4 \mathrm{M}$ and for each parameter was carried out between groups and the groups which showed significant different $(p$-Value $<0.05)$ were defined by common alphabetic letters 


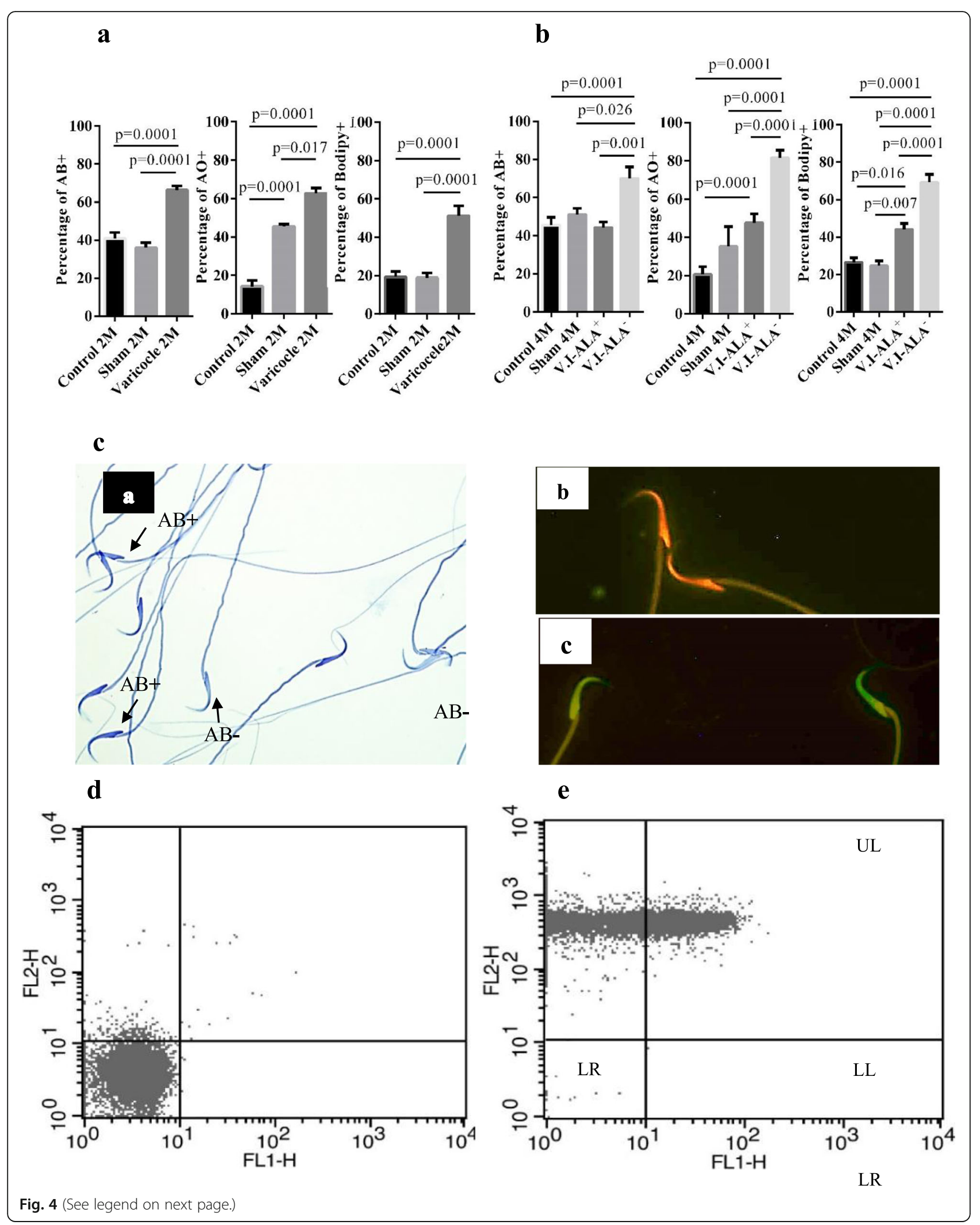


(See figure on previous page.)

Fig. 4 Evaluation of sperm functional tests. Legend: Aniline blue, Acridin orange and BODIPY staining at a) 2 month and b) 4 months postsurgery. Aniline blue, acridine orange and bodipy tests all indicated a significant increase in sperm alterations at $2 \mathrm{M}$ varicocele compared to the $2 \mathrm{M}$ control and sham groups. At 4 months of $\mathrm{VCL}$, the percentage of aniline blue, acridine orange and bodipy positive spermatozoa were significantly higher in the V.I-ALA group compared to the treated group (V.I-ALA ${ }^{+}$) and the 4 M control and sham groups. Statistical analysis (one way ANOVA) for each time point ( 2 or $4 \mathrm{M}$ ) and for each parameter was carried out between groups and $p$-value is provided for the groups which showed significant difference. c) a) aniline blue staining, sperm heads with dark blue staining indicate anilin blue positive and light blue staining indicates anilin blue negative. b) acridin orange positive sperm heads show orange-red fluorescence light indicate damaged chromatin, c) acridin orange negative sperm heads that expose green fluorescence light indicate intact chromatin. D) Evaluation of lipid peroxidation by bodipy C11 staining, 2-D flow cytometry dot plot of fluorescence intensity, for each sample, approximately 10,000 sperm cells were counted. d) shows unstained sperms while e) shows stained ones. The upper right quadrant, represents C11 Bodipy positive spermatozoa at $530 \mathrm{~nm}$ in green fluorescence with a FL1 band pass (BP).AB+: anilin blue positive, AB-: anilin blue negative, AO+: acridin orange positive, ALA: Alpha lipoic acid, Bodipy +: Bodipy positive, LL: Lower left, LR: lower right, UL: Upper left, UR: upper right, M: month post-surgery or varicocele induction (V.I), V.I$\mathrm{ALA}^{+}$; varicocele rats treated with ALA for 2 to 4 month post induction of varicocele, V.I-ALA ${ }^{-}$: varicocele rats treated with water as solvent of ALA for 2 to 4 month post induction of varicocele. Magnification bar $(50 \mu \mathrm{m})$

activation of Jnk by its level of phosphorylation (p-Jnk) and the accumulation of the Gpx-4 protein (a target of Nrf2). We found that the p-Jnk content of the testes was significantly higher in the VCL group than in the control animals at 2 months of age. At the same age, we did not observe any variation in the representation of the Gpx-4 protein. At 4 months of age, neither p-Jnk nor Gpx-4 was significantly more represented in the VCL testes than in the testes of control animals. ALA supplementation did not change anything for these two targets in the VCL animals.

\section{GSH and NADPH contents}

As shown in Fig. 7, GSH and NADPH levels were not significantly different between the VCL $(10.20 \pm 1.67$, $0.13 \pm 0.03)$ and control $(14.36 \pm 0.18,0.14 \pm 0.05)$ groups at 2 months, while at 4 months GSH levels increased significantly in the V.I-ALA ${ }^{+}$group $(19.75 \pm 1.18,0.12 \pm$ $0.04)$ compared to the control group (7.50 $\pm 1.44 ; p=$ $0.0001)$ and the VCL $\mathrm{ALA}^{-}$group $(12.25 \pm 0.47 ; p=$ $0.004)$.

\section{Discussion}

Despite the clearly established link between VCL and male infertility, VCL has remained a subject of debate for more than half a century. This is in part due to an incomplete understanding of the molecular mechanisms at stake. Among the underlying molecular mechanisms, the high level of ROS that accompanies VCL appears to play a key role in its etiology $[9,21]$. ROS can initiate different cell death pathways such as apoptosis, necrosis and also ferroptosis [22, 23]. This present study aimed to show whether ferroptosis is involved in VCL in a

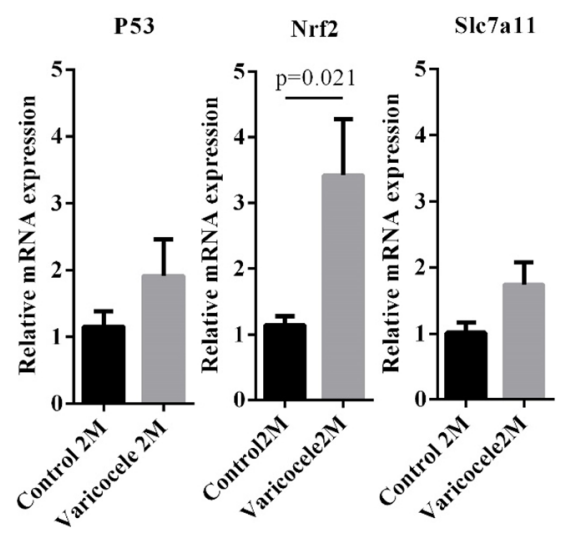

b

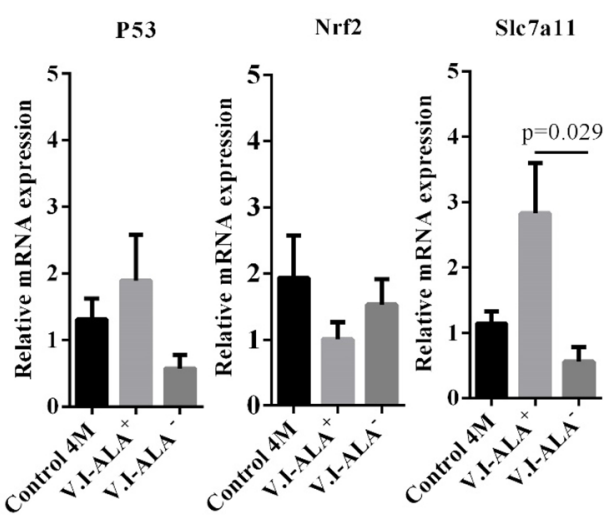

Fig. 5 Comparison of relative mRNA expression. Legend: Comparison of relative expression of P53, Nrf2 and S/c7a11 mRNA in different groups at 2 (a) and 4 months (b) post induction varicocele. The relative expression of Nrf2 showed a significant increase in the varicocele group compared to the $2 \mathrm{M}$ control group. At 4 months, the relative expression of SIC7a11 was significantly increased in the treated group (V.I-ALA ${ }^{+}$) compared to the $4 \mathrm{M}$ varicocele group (V.I-ALA-). M: month post-surgery or varicocele induction, Nrf2: Nuclear factor erythroid 2-related factor 2, V.I-ALA+: varicocele rats treated with ALA for 2 to 4 months post induction of varicocele, V.I-ALA ${ }^{-}$: varicocele rats treated with water as solvent of ALA for 2 to 4 months post induction of varicocele. Statistical analyses (independent sample T-test) for 2 months, (one way ANOVA) for $4 \mathrm{M}$ samples, for each parameter were carried out between groups and $p$-value is provided for the groups which showed significant difference 


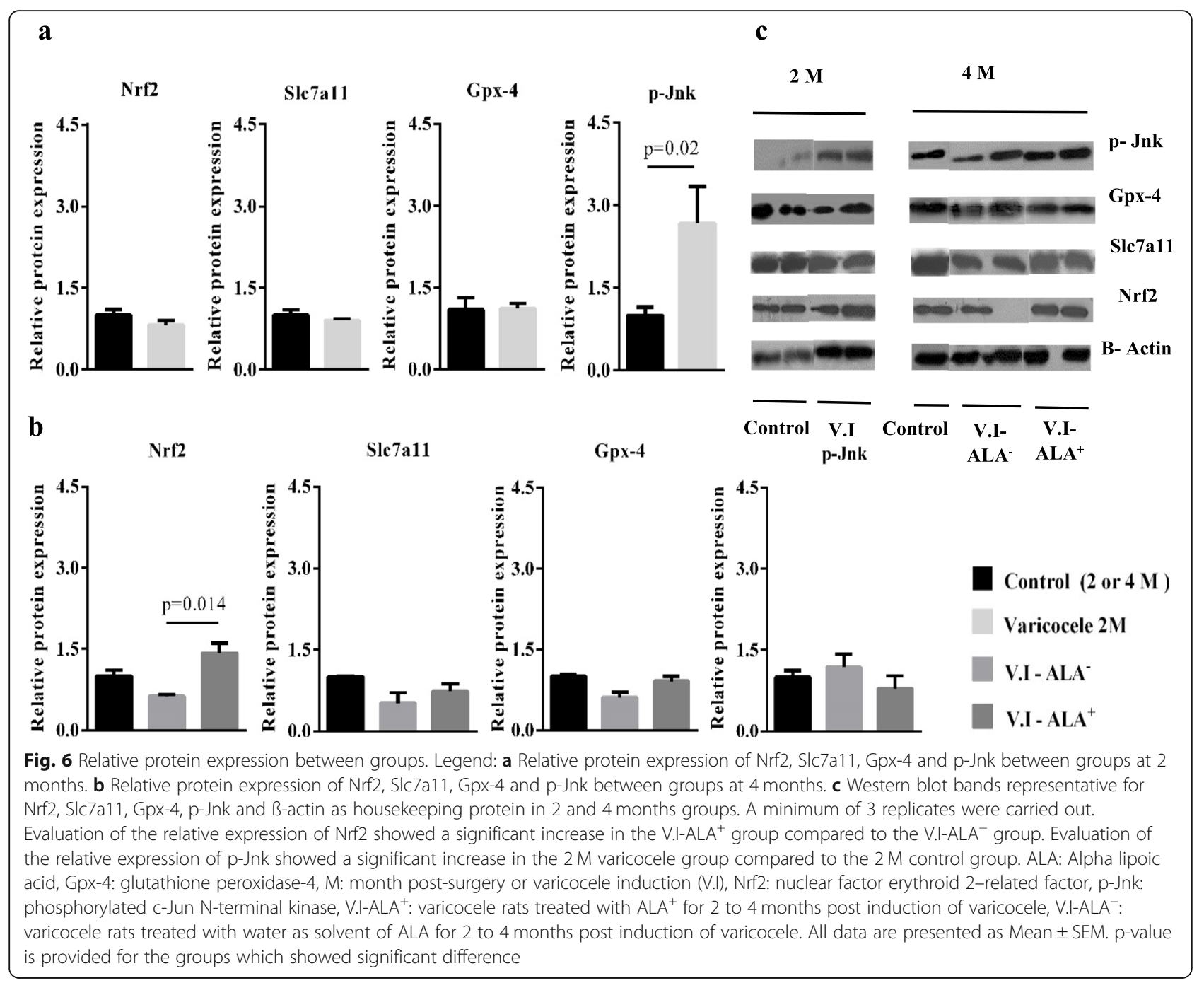

a

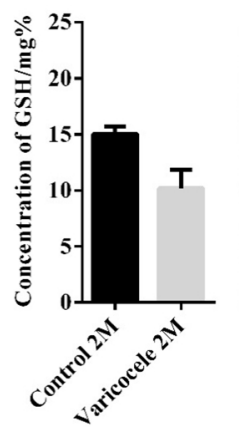

b $\mathrm{p}=0.0001$

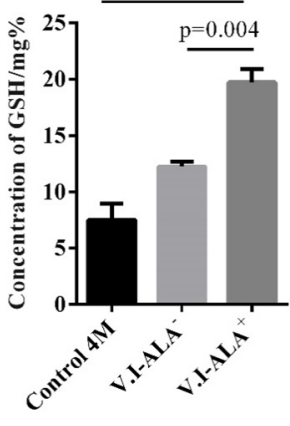

c

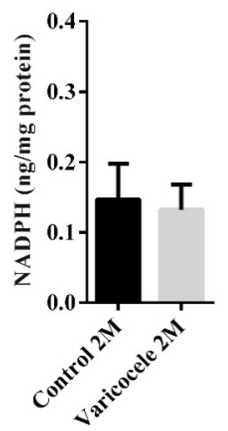

d

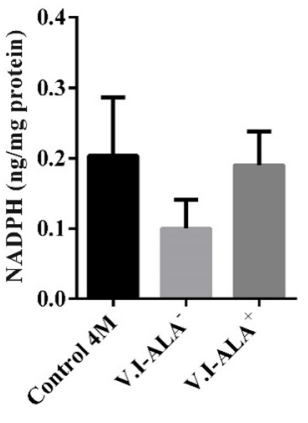

Fig. $7 \mathrm{GSH}$ and NADPH content in the different groups of animals. Legend: Evaluation of GSH content in a $2 \mathrm{M}$ group and $\mathbf{b} 4 \mathrm{M}$ group. Evaluation of NADPH content in $\mathbf{c} 2 \mathrm{M}$ group and $\mathbf{d} 4 \mathrm{M}$ group. Evaluation of the GSH concentration showed a significant increase in the V.I-ALA group compared to the V.I-ALA ${ }^{-}$group and the $4 \mathrm{M}$ control group. ALA: Alpha lipoic acid, GSH: Glutathione, M: month post-surgery or varicocele induction (V.I), NADPH: Reduced nicotinamide adenine dinucleotide phosphate, V.I-ALA ${ }^{+}$: varicocele rats treated with ALA for 2 to 4 months post induction of varicocele, V.I-ALA ${ }^{-}$: varicocele rats treated with water as solvent of ALA for 2 to 4 months post induction of varicocele. All data are presented as Mean \pm SEM. $p$-value is provided for the groups which showed significant difference 
particular in the light that iron was shown to accumulate within the VCL testis [9].

We first confirmed in a well-established and controlled rat VCL model that we found all the sperm characteristics of VCL including: reduction in classical spermatic parameters (mean concentration, normal morphology, motility), increased loss of spermatic chromatin integrity (assessed by the higher presence of residual histones), and increased lipid peroxidation and DNA damage 2 months after surgery-induced VCL These characteristics are largely attributable to oxidative stress generated by the VCL situation [12, 24-26]. In addition, we also confirm that the iron content was significantly increased in the testes of VCL animals (by 5 -fold and by 7 -fold respectively in 2 and 4 months old animals) compared to the control group. This situation, where both ROS and iron are in excess, makes it quite possible to induce ferroptosis in the VCL testis.

As stated in the introduction, the molecular pathway of ferroptosis is relatively distinct from that of the apoptosis pathway. In particular, p-Jnk, indirectly by regulating p53 transcription and activity, plays a key role in the ferroptosis pathway by inhibiting the Nrf2-mediated antioxidant response. However, despite the fact that Jnk kinase activity seems necessary for ferroptosis, its exact involvement has yet to be elucidated [27-29]. In this context, as understood to date, a decrease in the expression of Nrf2 target genes such as Slc7a11 and Gpx-4 should be expected [30, 31]. We show here that, in agreement with the above scenario, the activated protein p-Jnk was significantly more represented in the VCL testis group at 2 months of age. Regarding Nrf2, Nrf2 mRNA accumulation was found to be higher in the testis of 2 months-old VCL animals when compared to control testis at the same age but this was not followed by an elevated level of Nrf2 protein. Concurring with the unchanged level of Nrf2 transcriptional activator of antioxidant genes, we show that one of its well-known target gene, Gpx-4, is not activated in the VCL testis (as the GPx4 content of the VCL testis did not change neither in 2 months nor in 4 months groups). Furthermore, since neither GSH nor NADPH levels were modified in the 2 months nor 4 months Varicocele-testis this allows us to suggest that the classical antioxidant response is not significantly activated as GSH and NADPH are the cofactors necessary for the recycling of the Gpx enzymatic family in particular. In addition, following the assumed scenario, one would expect $\mathrm{p}$-Jnk increased level to result in diminished expression of Slc7a11. In contrast to what was expected, we observed an increased accumulation of Slc7a11 mRNA in the 2 months VCL testis when compared to control testis at the same age.

Taken together, these data strongly suggest that despite intrinsic characteristics that would favors the induction of ferroptosis (i.e., high iron content, oxidative stress), ferroptosis is not active in the VCL testis. However, one should be cautious with such a statement as it is known that in the VCL, the testis is not homogeneously affected by the stress response. While some testicular regions are severely affected to the point that it leads to spermatogenesis arrest and tubular destructuring, other parts of the VCL testis are much less damaged and still support spermatogenesis, although under stress [32]. In this mixed context, it is possible that the molecular changes that occur in areas of severe VCL damage are levelled out by areas of mild damage. This mixed context in terms of severity may also explain why some people with VCL are fertile while others are infertile.

Considering the potential beneficial effect of ALA supplementation on the VCL testis, we observed that ALA significantly improved sperm parameters and Johnson's score. ALA also reduced the loss of sperm nuclear integrity, resulting in better nuclear condensation and a lower level of DNA fragmentation. Finally, ALA also helped reduce sperm membrane lipid peroxidation. Overall, these beneficial effects of ALA on the VCL rat testis argue for its use as adjunctive therapy in VCL treatment options. This is consistent with our recent clinical trial showing that ALA supplementation after varicocelectomy improves sperm parameters [33]. ALA had no significant effect on Jnk phosphorylation, although it tended to be slightly reduced. However, ALA increased the Nrf2 content of the testis, which most likely explains the observed increase in Slc7a11 and Gpx-4 protein levels in the testes of ALA supplemented VCL rats. Similarly, ALA supplementation resulted in an increase in testicular GSH levels. Taken together, these effects are consistent with the known beneficial impact of ALA on Nrf2mediated antioxidant response [34]. Some reports have already suggested that Nrf2 may act as an antiferroptotic protein by stimulating the antioxidant response [7, 35]. Indeed, a recent study showed that MPP (1-methyl-4-phenylpyridinium: Parkinson's disease inducer) in PC12 cells induce oxidation and ferroptosis and that ALA was capable of reversing oxidation and ferroptosis markers [36]. Thus, we can hypothesize that the sensitive Nrf2 testicular pathway may function as a blocker of ferroptosis in V.I-ALA ${ }^{+}$, by further inducing the testicular Nrf2 pathway, may be a way to further protect the testis from Varicocele-mediated damage. In addition to its reinforcing effect on the Nrf2-mediated antioxidant testicular response, ALA may also have other beneficial effects on the VCL testis, helping it to stay away from ferroptosis. Indeed, ALA is known to function as a chelator for transition metals such as Fe and $\mathrm{Cu}[37,38]$. This may well explain why we observed a reduced level of $\mathrm{Fe}^{3+}$ in ALA supplemented VCL rats (at 4 months of age compared to non-supplemented 
rats). In addition, ALA has been reported to protect enzymatic and non-enzymatic antioxidants, including coenzyme Q10, GSSG, vitamins C and E [39], to capture ROS and nitrogen species, and to act as a cofactor for enzymes, particularly those required for the Krebs cycle $[40,41]$. Overall, ALA may help, in the case of the VCL testis, to preserve spermatozoa from oxidative damage that is closely related to motility and viability losses.

\section{Conclusion}

The data presented here are not in support of a clear ferroptosis situation in the rat VCL testis. It is important to note that this could be due to the heterogeneous context of the VCL testis showing regional damages eventually masking the detection of the ferroptosis classical molecular markers. It may be possible to clarify the situation in the future through tissue laser capture experiments to differentiate the presence of ferroptose markers in intact and damaged seminiferous tubules. We also show here that ALA supplementation in situation of VCL could be a pertinent option as ALA was shown to stimulate the Nrf2-mediated testis antioxidant response leading to improved spermatozoa structural and functional parameters. Whether an iron chelator such as Deferasirox (DFX), in addition to ALA supplementation, could benefit patients with VCL will have to await further validation.

\section{Abbreviations}

AB: Aniline blue; AO: Acridin orange; ALA: Alpha-lipoic acid; bp: Base pair; ${ }^{\circ} \mathrm{C}$ : Degrees Celsius; D: Disrupted spermatogenesis; DFX: Deferasirox; EH: Epithelium height; GSH: Glutathione; GPX-4: Gluthation peroxidase-4; JS: Johnson score; LL: Lower left; LR: Lower right; UL: Upper left; UR: Upper right; M: Month post-surgery or varicocele induction; MI: Mitotic index; MPP: 1-methyl-4-phenylpyridinium; n: Number of rats; NADPH: Reduced nicotinamide adenine dinucleotide phosphate; NRF2: Nuclear factor erythroid 2-related factor 2; p-JNK: Phosphorylated c-Jun N-terminal kinase; SP: Spermatogenesis percentage; TD: Tubular diameter; V: Vacuolated seminiferous epithelium; VCL: Varicocele; V.I: Varicocele induction; V.I$\mathrm{ALA}^{+}$: Varicocele rats treated with ALA for 2 to 4-month post induction of varicocele; V.I-ALA ${ }^{-}$: Varicocele rats treated with water as solvent of ALA for 2 to 4-month post induction of varicocele

\section{Acknowledgments}

We would like to precise our sincere gratitude to Mrs. Hosseini, Mr. Rahmani, Miss Eskandari and Dr. Sadeghi and all other stuffs of andrology laboratory of Royan institute for their encouragements and support to fulfill the objectives of this research. We are thankful to the Royan institute in Isfahan, Iran for providing laboratory instruments and possibility to carry out all tests and animal facilities.

\section{Authors' contributions}

ES performed experiments, analyzed data, wrote the manuscript, MHN designed the study and experiments, critically analyzed the data and rewrote the manuscript. FS and KP censoriously reviewed the manuscript and data analyzing. All authors confirm final version of the manuscript. The author(s) read and approved the final manuscript.

\section{Availability of data and materials}

The datasets used and/or analyzed during the current study are available from the corresponding author on reasonable request.

Ethics approval and consent to participate

This study has been approved by the Institutional Review Board of the ROYAN Institute (IR.ACECR.ROYAN.REC.1397.149).

\section{Consent for publication}

Not applicable.

\section{Competing interests}

The authors declare that they have no competing interests.

Received: 4 October 2020 Accepted: 4 February 2021

Published online: 01 April 2021

\section{References}

1. Dixon SJ, Lemberg KM, Lamprecht MR, Skouta R, Zaitsev EM, Gleason CE, et al. Ferroptosis: an iron-dependent form of nonapoptotic cell death. Cell. 2012;149(5):1060-72. https://doi.org/10.1016/j.cell.2012.03.042.

2. Cao JY, Dixon SJ. Mechanisms of ferroptosis. Cell Mol Life Sci. 2016;73(1112):2195-209. https://doi.org/10.1007/s00018-016-2194-1.

3. Xie Y, Hou W, Song X, Yu Y, Huang J, Sun X, et al. Ferroptosis: process and function. Cell Death Differ. 2016;23(3):369-79. https://doi.org/10.1038/cdd.2 015.158.

4. Yang WS, Stockwell BR. Synthetic lethal screening identifies compounds activating iron-dependent, nonapoptotic cell death in oncogenic-RASharboring cancer cells. Chem Biol. 2008;15(3):234-45. https://doi.org/10.101 6/j.chembiol.2008.02.010

5. Li T, Kon N, Jiang L, Tan M, Ludwig T, Zhao Y, Baer R, Gu W. Tumor suppression in the absence of p53-mediated cell-cycle arrest, apoptosis, and senescence. Cell. 2012;149(6):1269-83. https://doi.org/10.1016/j.cell.2012.04. 026.

6. Nie J, Lin B, Zhou M, Wu L, Zheng T. Role of ferroptosis in hepatocellular carcinoma. J Cancer Res Clin Oncol. 2018;144(12):2329-37. https://doi.org/1 0.1007/s00432-018-2740-3.

7. Sun X, Ou Z, Chen R, Niu X, Chen D, Kang R, Tang D. Activation of the p62Keap1-NRF2 pathway protects against ferroptosis in hepatocellular carcinoma cells. Hepatology. 2016;63(1):173-84. https://doi.org/10.1002/ hep.28251.

8. Friedmann Angeli JP, Schneider M, Proneth B, Tyurina YY, Tyurin VA, Hammond VJ, et al. Inactivation of the ferroptosis regulator Gpx4 triggers acute renal failure in mice. Nat Cell Biol. 2014;16(12):1180-91. https://doi. org/10.1038/ncb3064.

9. Gholirad S, Razi M, Hassani BH. Tracing of zinc and iron in experimentally induced varicocele: correlation with oxidative, nitrosative and carbonyl stress. Andrologia. 2017;49(6). https://doi.org/10.1111/and.12687.

10. Shaygannia E, Tavalaee M, Akhavanfarid GR, Rahimi M, Dattilo M, NasrEsfahani MH. Alpha-Lipoic acid improves the testicular dysfunction in rats induced by varicocele. Andrologia. 2018;50(9):e13085. https://doi.org/1 0.1111 /and. 13085

11. Turner $T$. The study of varicocele through the use of animal models. Hum Reprod Update. 2001;7(1):78-84. https://doi.org/10.1093/humupd/7.1.78.

12. Razi M, Malekinejad H. Varicocele-Induced Infertility in Animal Models. Int J Fertil Steril. 2015;9(2):141-9. https://doi.org/10.22074/ijfs.2015.4234.

13. Xie BG, Li J, Zhu WJ. Pathological changes of testicular tissue in normal adult mice: a retrospective analysis. Exp Ther Med. 2014;7(3):654-6. https:// doi.org/10.3892/etm.2014.1481

14. Johnsen SG. Testicular biopsy score count--a method for registration of spermatogenesis in human testes: normal values and results in 335 hypogonadal males. Hormones. 1970;1(1):2-25. https://doi.org/10.1159/0001 78170.

15. Afiyani AA, Deemeh MR, Tavalaee M, Razi M, Bahadorani M, Shokrollahi B, Nasr-Esfahani MH. Evaluation of heat-shock protein A2 (HSPA2) in male rats before and after varicocele induction. Mol Reprod Dev. 2014;81(8):766-76. https://doi.org/10.1002/mrd.22345.

16. Aitken RJ, Wingate JK, De luliis GN, McLaughlin EA. Analysis of lipid peroxidation in human spermatozoa using BODIPY C11. Mol Hum Reprod 2007;13(4):203-11. https://doi.org/10.1093/molehr/gal119. 
17. Yesil S, Sungu N, Kilicarslan A, Kuskonmaz SM, Kara H, Kucuk A, et al. Exenatide reduces oxidative stress and cell death in testis in iron overload rat model. Exp Ther Med. 2018;16(6):4349-56. https://doi.org/10.3892/etm.2 018.6795 .

18. Li GY, Xie P, Li HY, Hao L, Xiong Q, Qiu T. Involment of p53, Bax, and BCl-2 pathway in microcystins-induced apoptosis in rat testis. Environ Toxicol. 2011;26(2):111-7. https://doi.org/10.1002/tox.20532.

19. Aghajanpour S, Ghaedi K, Salamian A, Deemeh MR, Tavalaee M, Moshtaghian J, et al. Quantitative expression of phospholipase C zeta, as an index to assess fertilization potential of a semen sample. Hum Reprod. 2011; 26(11):2950-6. https://doi.org/10.1093/humrep/der285.

20. Ellman GL, Courtney KD, Andres VJr, Feather-Stone RM. A new and rapid colorimetric determination of acetylcholinesterase activity. Biochem Pharmacol. 1961;7:88-95. https://doi.org/10.1016/0006-2952(61)90145-9.

21. Cho CL, Esteves SC, Agarwal A. Novel insights into the pathophysiology of varicocele and its association with reactive oxygen species and sperm DNA fragmentation. Asian J Androl. 2016;18(2):186-93. https://doi.org/10.4103/1 008-682X.170441.

22. Lee YS, Lee DH, Choudry HA, Bartlett DL, Lee YJ. Ferroptosis-induced endoplasmic reticulum stress: cross-talk between Ferroptosis and apoptosis. Mol cancer research. 2018;16(7):1073-6. https://doi.org/10.1158/1541-7786. MCR-18-00556.

23. Su LJ, Zhang JH, Gomez $H$, Murugan $R$, Hong $X, X u$ D, et al. Reactive Oxygen Species-Induced Lipid Peroxidation in Apoptosis, Autophagy, and Ferroptosis. Oxid Med Cell Longev. 2019;2019:5080843. https://doi.org/10.11 55/2019/5080843.

24. Dieamant F, Petersen CG, Mauri AL, Conmar V, Mattila M, Vagnini LD, et al. Semen parameters in men with varicocele: DNA fragmentation, chromatin packaging, mitochondrial membrane potential, and apoptosis. JBRA Assist Reprod. 2017;21(4):295-301. https://doi.org/10.5935/1518-0557.20170053.

25. Paduch DA, Skoog SJ. Current management of adolescent varicocele. Rev Urol. 2001;3(3):120-33.

26. Krishna Reddy SV, Shaik AB, Sailaja S, Venkataramanaiah M. Outcome of Varicocelectomy with different degrees of clinical Varicocele in infertile male. Adv in Androl. 2015:1-9. https://doi.org/10.1155/2015/432950.

27. Dhanasekaran DN, Reddy EP. JNK-signaling: A multiplexing hub in programmed cell death. Genes Cancer. 2017;8(9-10):682-94. https://doi. org/10.18632/genesandcancer.

28. Wang Y, Guo SH, Shang XJ, Yu LS, Zhu JW, Zhao A, et al. Triptolide induces Sertoli cell apoptosis in mice via ROS/JNK-dependent activation of the mitochondrial pathway and inhibition of Nrf2-mediated antioxidant response. Acta Pharmacol Sin. 2018;39(2):311-27. https://doi.org/10.1038/a ps.2017.95.

29. Ye F, Chai $W$, Xie M, Yang M, Yu Y, Cao L, et al. HMGB1 regulates erastininduced ferroptosis via RAS-JNK/p38 signaling in HL-60/NRASQ61L cells. Am J Cancer Res. 2019:9(4):730-9.

30. Kajarabille N, Latunde-Dada GO. Programmed cell-death by Ferroptosis: antioxidants as Mitigators. Int J Mol Sci. 2019;20(19):4968. https://doi.org/1 0.3390/ijms20194968.

31. Hao S, Liang B, Huang Q, Dong S, Wu Z, He W, et al. Metabolic networks in ferroptosis. Oncol Lett. 2018;15(4):5405-11. https://doi.org/10.3892/ol.2018. 8066.

32. Agarwal A, Sharma RK, Desai NR, Prabakaran S, Tavares A, Sabanegh E. Role of oxidative stress in pathogenesis of varicocele and infertility. Urology. 2009:73(3):461-9. https://doi.org/10.1016/j.urology.2008.07.053.

33. Abbasi B, Molavi N, Tavalaee M, Abbasi H, Nasr-Esfahani MH. Alpha-lipoic acid improves sperm motility in infertile men after varicocelectomy: a tripleblind randomized controlled trial. Reprod BioMed Online. 2020;41(6):108491. https://doi.org/10.1016/j.rbmo.2020.08.013.

34. Zhang J, Zhou X, Wu W, Wang J, Xie H, Wu Z. Regeneration of glutathione by a-lipoic acid via Nrf2/ARE signaling pathway alleviates cadmium-induced HepG2 cell toxicity. Environ Toxicol Pharmacol. 2017;51:30-7. https://doi. org/10.1016/j.etap.2017.02.022.

35. Shin D, Kim EH, Lee J, Roh JL. Nrf2 inhibition reverses resistance to GPX4 inhibitor-induced ferroptosis in head and neck cancer. Free Radic Biol Med. 2018:129:454-62. https://doi.org/10.1016/j.freeradbiomed.2018.10.426.

36. Liu L, Yang S, Wang H. Alpha lipoic acid alleviates ferroptosis in the MPP+ -induced PC12 cells via activating the PI3K/Akt/Nrf2 pathway. Cell Biol Int. 2020. https://doi.org/10.1002/cbin.

37. Camiolo G, Tibullo D, Giallongo C, Romano A, Parrinello NL, Musumeci G, et al. a-Lipoic acid reduces Iron-induced toxicity and oxidative stress in a model of Iron overload. Int J Mol Sci. 2019;20(3):609. https://doi.org/10.3390/ ijms20030609.

38. Selvakumar E, Prahalathan C, Sudharsan PT, Varalakshmi P. Chemoprotective effect of lipoic acid against cyclophosphamide-induced changes in the rat sperm. Toxicology. 2006;217(1):71-8. https://doi.org/10.1016/j.tox.2005.08.020.

39. Borowczyk K, Krawczyk M, Kubalczyk P, Chwatko G. Determination of lipoic acid in biological samples. Bioanalysis. 2015;7(14):1785-98. https://doi.org/1 0.4155/bio.15.95.

40. Hagen TM, Ingersoll RT, Lykkesfeldt J, Liu J, Wehr CM, Vinarsky V, et al. (R)alpha-lipoic acid-supplemented old rats have improved mitochondrial function, decreased oxidative damage, and increased metabolic rate. FASEB J. 1999;13(2):411-8. https://doi.org/10.1096/fasebj.13.2.411.

41. Haghighian HK, Haidari F, Mohammadi-Asl J, Dadfar M. Randomized, tripleblind, placebo-controlled clinical trial examining the effects of alpha-lipoic acid supplement on the spermatogram and seminal oxidative stress in infertile men. Fertil Steril. 2015;104(2):318-24. https://doi.org/10.1016/j. fertnstert.2015.05.014.

\section{Publisher's Note}

Springer Nature remains neutral with regard to jurisdictional claims in published maps and institutional affiliations.
Ready to submit your research? Choose BMC and benefit from:

- fast, convenient online submission

- thorough peer review by experienced researchers in your field

- rapid publication on acceptance

- support for research data, including large and complex data types

- gold Open Access which fosters wider collaboration and increased citations

- maximum visibility for your research: over $100 \mathrm{M}$ website views per year

At BMC, research is always in progress.

Learn more biomedcentral.com/submissions 